\title{
Особенности температурной стабильности сопротивления омических контактов к наногетероструктурам на основе GaAs и GaN
}

\author{
(C) В.И. Егоркин, В.Е. Земляков, А.В. Неженцев, А.А. Зайцев, В.И. Гармаш
}

Национальный исследовательский университет „МИЭТ“, 124498 Зеленоград, Москва, Россия

E-mail: alekseyy_nejencev@rambler.ru

Поступила в Редакцию 13 января 2021 г. В окончательной редакции 26 июля 2021 r. Принята к публикации 17 августа 2021 г.

\begin{abstract}
Проведено исследование температурной зависимости сопротивления омических контактов на основе металлизации $\mathrm{Ge} / \mathrm{Au} / \mathrm{Ni} / \mathrm{Au}$ к наногетероструктурам арсенида галлия $(\mathrm{GaAs})$, а также на основе металлизаций $\mathrm{Ti} / \mathrm{Al} / \mathrm{Ni} / \mathrm{Au}$ к наногетероструктурам нитрида галлия $(\mathrm{GaN})$ на кремниевой подложке. Установлено, что оптимизация методов вжигания позволяет получать омические контакты с токопереносом по закону, соответствующему механизму полевой эмиссии. Показано, что термостабильность омических контактов для транзисторов и мезарезисторов проявляет пороговое поведение в зависимости от температуры термообработки, и выявлен оптимум по температурной стабильности и минимуму контактного сопротивления.
\end{abstract}

Ключевые слова: омический контакт, арсенид галлия, нитрид галлия.

DOI: 10.21883/FTP.2021.12.51716.9603

\section{1. Введение}

Транзисторы с высокой подвижностью электронов на основе арсенида галлия (GaAs) и нитрида галлия $(\mathrm{GaN})$ последние двадцать лет активно развиваются и становятся основой компонентной базы современной СВЧ электроники и силовой электроники. Для надежной работы полупроводниковых устройств необходимо, чтобы параметры транзисторов и мезарезисторов оставались постоянными при различных температурах. Поскольку омические контакты являются составной частью транзисторов и мезарезисторов на основе полупроводниковых линий, понимание зависимости сопротивления омического контакта от температуры является важной задачей для стабильной работы приборов $[1,2]$.

Наиболее распространенными металлическими схемами для изготовления омических контактов к эпитаксиальным слоям арсенида галлия являются схемы на основе эвтектического сплава германия и золота $(\mathrm{AuGe})$. Такой контакт формируется специальной термической обработкой при температурах $\sim 380^{\circ} \mathrm{C}-$ вжиганием. В ходе этого процесса происходят жидкофазные реакции, которые определяют электрические свойства контакта. Термостабильность омических контактов на основе AuGe к арсениду галлия достигается использованием металлизации на основе тугоплавких материалов [3-5], или за счет оптимизации режимов термической обработки [6,7].

К наногетероструктурам на основе нитрида галлия в качестве контактной чаще всего используют металлизацию на основе Ti/Al [8-11]. Принято считать, что снижение контактного сопротивления после отжига является следствием образования слоя TiN на границе раздела металл-полупроводник. Это приводит к образованию вакансий азота в полупроводнике, действующих как донорная примесь [12]. В последнее десятилетие произошел существенный прогресс в технологии роста гетероструктур на основе нитрида галлия на кремниевой подложке [13-15]. Кремний обладает высокой теплопроводностью, это существенно увеличивает отвод тепла в сравнении с арсенидом галлия, что в свою очередь позволяет изготавливать мощные нитридгаллиевые транзисторы. При изготовлении омических контактов на основе Ti/Al к нитриду галлия проводится высокотемпературная термическая обработка. В исследованиях, посвященных изучению механизма переноса тока, выделяют термополевую эмиссию [1,16-18].

При осаждении слоев металлизации на границе контакта металл-полупроводник образуется потенциальный барьер. В случае омического контакта он не оказывает заметного влияния - либо его высота минимальна, либо барьер имеет небольшую ширину. Зависимость контактного сопротивления от температуры определяется механизмом переноса тока в омическом контакте, всего выделяют три механизма: термоэмиссия, полевая эмиссия и термополевая эмиссия $[19,20]$.

Построив экспериментально зависимость величины контактного сопротивления от температуры, можно определить механизм протекания тока в омическом контакте. Если ток в омическом контакте протекает по механизму полевой эмиссии, то уровень сопротивления не зависит от температуры. В литературных источниках приводятся исследования, согласно которым основным механизмом переноса тока в омических контактах к $\mathrm{GaAs}$ и $\mathrm{GaN}$ являются термополевая эмиссия и металлический тип проводимости [20,21]. Потому для достижения высокой термостабильности необходимо определить оптимальные параметры изготовления омических контактов к наноструктурам на основе $\mathrm{GaN}$ и $\mathrm{GaAs}$, ток в которых протекает по закону полевой эмиссии. 


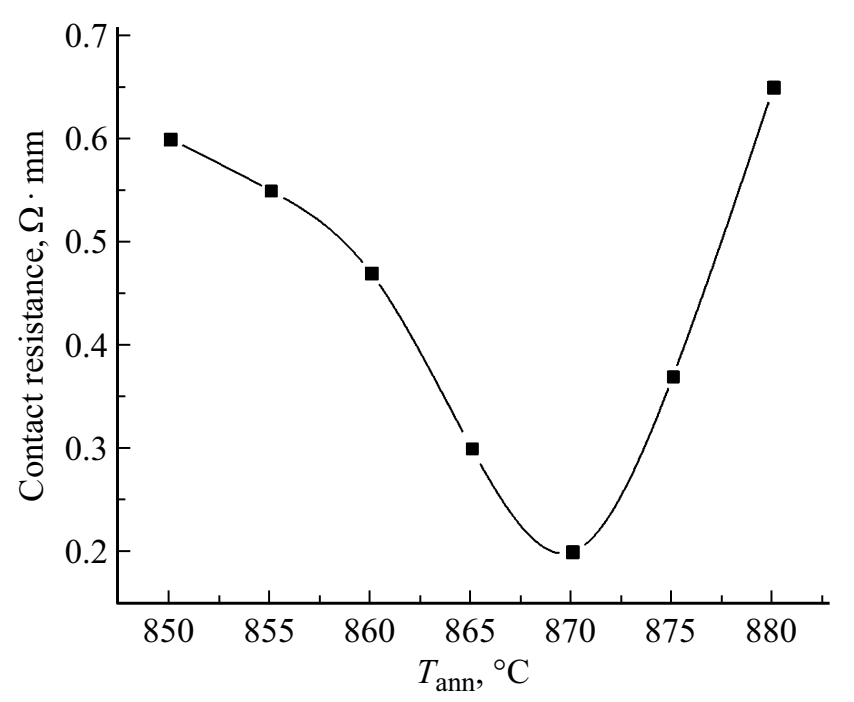

Рис. 1. Зависимость сопротивления омических контактов на основе металлизации $\mathrm{Ti} / \mathrm{Al} / \mathrm{Ni} / \mathrm{Au}$ к $\mathrm{GaN}$ от температуры вжигания. Время вжигания $30 \mathrm{c}$.

В данной работе исследованы металлизации $\mathrm{Ti} / \mathrm{Al} / \mathrm{Ni} / \mathrm{Au} \quad(20 / 100 / 40 / 50$ нм $)$ для изготовления омических контактов к нитриду галлия и $\mathrm{Ge} / \mathrm{Au} / \mathrm{Ni} / \mathrm{Au}$ $(5 / 10 / 10 / 150$ нм $)$ к арсениду галлия. Исследовали влияние температуры на величину сопротивления омического контакта, и определяли механизм переноса тока через границу раздела металл-полупроводник.

\section{2. Эксперимент}

Для изготовления образцов была использована контактная фотолитография, процесс формирования резистной маски проводился в соответствии с [22]. Металлизации $\mathrm{Ti} / \mathrm{Al} / \mathrm{Ni} / \mathrm{Au}$ и $\mathrm{Ge} / \mathrm{Au} / \mathrm{Ni} / \mathrm{Au}$ формировались на установке электронно-лучевого напыления Kurt J. Lesker. Для проведения процессов термической обработки омических контактов к нитриду галлия использовали промышленную печь быстрого термического отжига Unitemp 1200, к арсениду галлия - установку термической обработки оригинальной конструкции [23].

Исследование зависимости контактного сопротивления от температуры проводилось на зондовой станции с подогреваемым столиком в атмосфере окружающей среды. Использовался резистивный нагреватель, расположенный под измерительным столиком. Температура определялась с помощью термопары, находящейся в контакте со столиком.

Образцы омических контактов к арсениду галлия были изготовлены в соответствии с технологическими параметрами, приведенными в [24], осуществлялось вжигание в течение 1 мин при температурах $T_{\text {ann }}=278$, 398 и $450^{\circ} \mathrm{C}$.

Детально исследована зависимость контактного сопротивления на основе металлизации $\mathrm{Ti} / \mathrm{Al} / \mathrm{Ni} / \mathrm{Au}$ от температуры вжигания (рис. 1). Минимальное значение контактного сопротивления было получено при температуре $870^{\circ} \mathrm{C}$ и составило $0.2 \mathrm{OM} \cdot$ мм.

Далее образцы, полученные при температурах вжигания 850, 870 и $880^{\circ} \mathrm{C}$, были подвергнуты нагреву с контролем величины контактного сопротивления.

\section{3. Результаты}

Из рис. 2 видно, что сопротивление омических контактов к арсениду галлия, полученных при температуре вжигания $398^{\circ} \mathrm{C}$, практически не зависит от температуры измерения. Для омических контактов, полу-

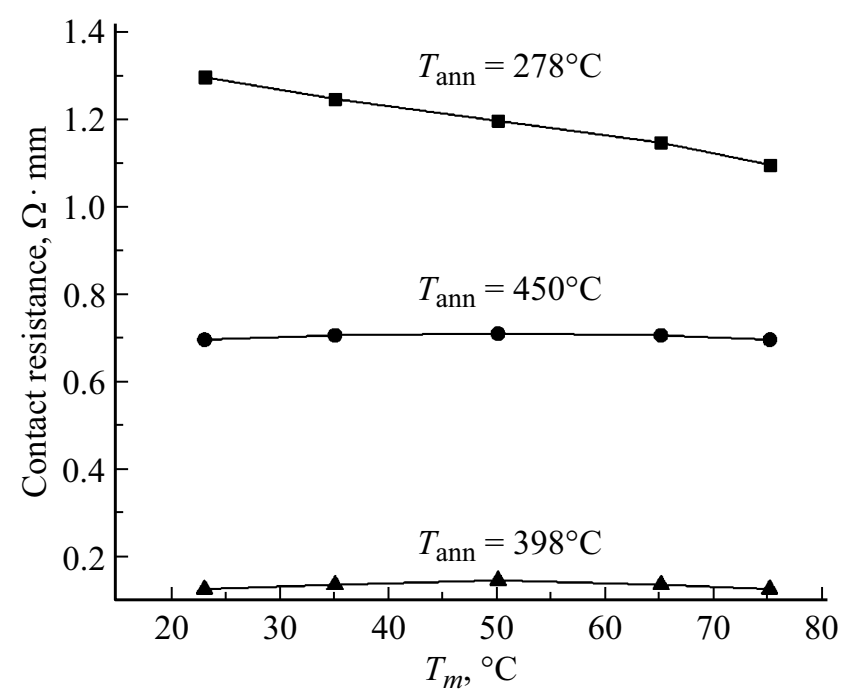

Рис. 2. Зависимость от температуры измерения $T_{m}$ сопротивления омических контактов на основе металлизации $\mathrm{Ge} / \mathrm{Au} / \mathrm{Ni} / \mathrm{Au}$ к $\mathrm{GaAs}$, полученных при различных температурах вжигания $T_{\mathrm{ann}}$.

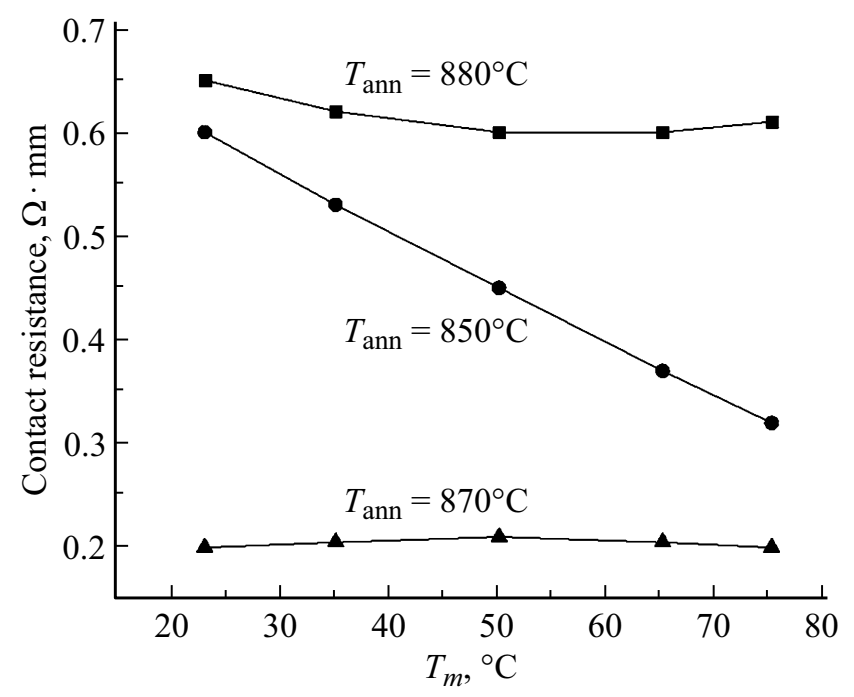

Рис. 3. Зависимость от температуры измерения $T_{m}$ сопротивления омических контактов к $\mathrm{GaN}$ на основе металлизации $\mathrm{Ti} / \mathrm{Al} / \mathrm{Ni} / \mathrm{Au}$, полученных при различных температурах вжигания $T_{\text {ann. }}$. 
ченных при $278^{\circ} \mathrm{C}$, характерно уменьшение величины сопротивления с ростом температуры измерения, а для контактов, полученных при $450^{\circ} \mathrm{C}$, видим небольшое увеличение сопротивления с ростом температуры.

Омические контакты к наногетероструктурам $\mathrm{GaN}$ на основе металлизации $\mathrm{Ti} / \mathrm{Al} / \mathrm{Ni} / \mathrm{Au}$, полученные при температурах вжигания $<860^{\circ} \mathrm{C}$, показывают уменьшение контактного сопротивления в зависимости от температуры. Повышение температуры вжигания до 870 и $880^{\circ} \mathrm{C}$ резко снижает зависимость контактного сопротивления от температуры. Увеличение температуры термической обработки приводит к деградации уровня контактного сопротивления и самой полупроводниковой структуры, поэтому более высокие температуры вжигания не рассматривались.

Из рис. 2 и 3 видно, что уровень сопротивления полученных при оптимальных параметрах вжигания омических контактов не только минимален, но и остается постоянным с ростом температуры в указанном диапазоне. Исходя из теоретических представлений можно сделать вывод, что высокая термостабильность оптимизированных омических контактов определяется механизмом переноса тока через границу раздела металл/полупроводник - именно механизмом полевой эмиссии. Зависимость величины контактного сопротивления от температуры для образцов. отожженных не при оптимальных параметрах, свидетельствует о токопереносе в них по механизму термополевой эмиссии. Таким образом, оптимизация методов вжигания позволяет изменить механизм переноса тока с термополевой эмиссии на полевую.

\section{4. Заключение}

В ходе исследования воздействия температуры на величину сопротивления омических контактов к GaAs и $\mathrm{GaN}$ показана возможность получения термостабильных омических контактов. Установлено, что оптимизация методов вжигания позволяет получать омические контакты с механизмом переноса тока, соответствующим закону полевой эмиссии. Омический контакт на основе металлизации $\mathrm{AuGe}$ к $\mathrm{GaAs}$, полученный вжиганием в течение 60 с при температуре $398^{\circ} \mathrm{C}$, имеет минимальный уровень контактного сопротивления $(0.13 \mathrm{OM} \cdot \mathrm{MM})$, не зависящий от температуры. Омические контакты на основе $\mathrm{Ti} / \mathrm{Al}$ к $\mathrm{GaN}$, полученные при температуре вжигания $870^{\circ} \mathrm{C}$ в течение $30 \mathrm{c}$, термостобильны. Для металлизации $\mathrm{Ti} / \mathrm{Al} / \mathrm{Ni} / \mathrm{Au}$ минимальное сопротивление составило 0.2 Ом · мм. Термостабильность омических контактов для транзисторов и мезарезисторов проявляет пороговое поведение от температуры термообработки и показывает оптимум по температурной стабильности и минимум контактного сопротивления.

\section{Финансирование работы}

Полученные в статье результаты исследований достигнуты в ходе реализации проекта НИУ МИЭТ с использо- ванием мер государственной поддержки развития кооперации российских образовательных организаций высшего образования, государственных научных учреждений и организаций, реализующих комплексные проекты по созданию высокотехнологичного производства, предусмотренных постановлением Правительства Российской Федерации от апреля 2010 г. № 218. Название проекта НИУ МИЭТ „Разработка технологии и технологическая подготовка к производству кристаллов транзисторов на основе гетероструктур нитрида галлия на подложке кремния диаметром 150 мм для силовых преобразовательных модулей“. Соглашение № 075-11-2019-068 от 26 ноября 2019 г.

\section{Конфликт интересов}

Авторы заявляют, что у них нет конфликта интересов.

\section{Список литературы}

[1] F. Iucolano, G. Greco, F. Roccaforte. Appl. Phys. Lett., 103 (20), 201604 (2013).

[2] Z.H. Liu, S. Arulkumaran, G.I. Ng. Appl. Phys. Lett., 94 (14), 142105 (2009).

[3] T.C. Shen, G.B. Gao, H. Morkoc. J. Vacuum Sci. \& Technol. B: Microelectron. and Nanometer Structures Processing, Measurement, and Phenomena, 10 (5), 2113 (1992).

[4] P.H. Hao, L.C. Wang, F. Deng, S.S. Lau, J.Y. Cheng. J. Appl. Phys., 79 (8), 4211 (1996).

[5] A.M. Crook, E. Lind, Z. Griffith, M.J. Rodwell, J.D. Zimmerman, A.C. Gossard, S.R. Bank. Appl. Phys. Lett., 91 (19), 192114 (2007).

[6] M. Murakami. Sci. Technol. Adv. Mater., 3 (1), 1 (2002).

[7] A. Callegari, E.T.S. Pan, M. Murakami. Appl. Phys. Lett., 46 (12), 1141 (1985).

[8] Z. Fan, S.N. Mohammad, W. Kim, Ö. Aktas, A.E. Botchkarev, H. Morkoç. Appl. Phys. Lett., 68, 1672 (1996).

[9] A.N. Bright, P.J. Thomas, M. Weyland, D.M. Tricker, C.J. Humprhreys, R. Davies, J. Appl. Phys., 89, 3143 (2001).

[10] A. Motayed, R. Bathe, M.C. Wood, O.S. Diouf, R.D. Vispute, S.N. Mohammad. J. Appl. Phys., 93, 1087 (2003).

[11] M.W. Fay, G. Modlovan, N.J. Weston, P.D. Brown, I. Harrison, K.P. Hilton, A. Masterton, W. Wallis, R.S. Balmer, M.J. Uren, T. Martin. J. Appl. Phys., 96, 5588 (2004).

[12] J.S. Kwak, S.E. Mohney, J.Y. Lin, R.S. Kern. Semicond. Sci. Technol., 15, 756 (2000).

[13] C.L. Wu, J.C. Wang, M.H. Chan, T.T. Chen, S. Gwo. Appl. Phys. Lett., 83 (22), 4530 (2003).

[14] T.A. Rawdanowicz, J. Narayan. Appl. Phys. Lett., 85 (1), 133 (2004).

[15] J. Komiyama, Y. Abe, S. Suzuki, H. Nakanishi. Appl. Phys. Lett., $88(9), 091901$ (2006).

[16] Т.В. Бланк, Ю.А. Гольдберг. ФТП, 41 (11), 1281 (2007).

[17] F. Iucolano, F. Roccaforte, A. Alberti, C. Bongiorno, S. Di Franco, V. Raineri. J. Appl. Phys., 100 (12), 123706 (2006).

[18] N. Thierry-Jebali, O. Ménard, C. Dubois, D. Tournier, E. Collard, C. Brylinski, F. Cayrel, D. Alquier. Mater. Sci. Forum (Trans. Tech. Publications Ltd), 711, 208 (2012). 
[19] A.A. Lakhani, R.C. Potter, D.M. Beyea. Semicond. Sci. Technol., 3 (6), 605 (1988).

[20] G.S. Marlow, M.B. Das, L. Tongson. Solid-State Electron., 26 (4), 259 (1983).

[21] Т.В. Бланк, Ю.А. Гольдберг, О.В. Константинов, В.Г. Никитин, Е.А. Поссе. ЖТФ, 77 (2), 140 (2007).

[22] А.В. Неженцев, В.Е. Земляков, В.И. Егоркин, В.И. Гармаш. Электрон. техн., сер. 2, Полупроводниковые приборы, № 2-3, 96 (2015).

[23] В.И. Егоркин, В.Е. Земляков, А.В. Неженцев, В.И. Гармаш. Микроэлектроника, 46 (4), 295 (2017).

[24] В.И. Егоркин, В.Е. Земляков, А.В. Неженцев, В.И. Гармаш. Изв. вузов. Электроника, 23 (1), 15 (2018).

Редактор Л.В. Шаронова

\section{Temperature stability features of ohmic contacts resistance to GaAs and GaN based nanoheterostructures}

V.I. Egorkin, V.E. Zemlyakov, A.V. Nezhentsev, A.A. Zaitsev, V.I. Garmash

National Research University „MIET“, 124498 Zelenograd, Moscow, Russia

Abstract Temperature stability of $\mathrm{Ge} / \mathrm{Au} / \mathrm{Ni} / \mathrm{Au}$ ohmic contacts to $\mathrm{GaAs}$ nanoheterostructures and $\mathrm{Ti} / \mathrm{Al} / \mathrm{Ni} / \mathrm{Au}$ ohmic contacts to $\mathrm{GaN}$ nanoheterostructures on silicon substrates was investigated. It has been established that optimization of the annealing process made it possible to obtain ohmic contacts with field emission current flow mechanism. The thermal stability of ohmic contacts for transistors and mesa resistors demonstrated the threshold behavior of the heat treatment temperature. Optimum process parameters for temperature stability and minimum contact resistance were determined. 